\title{
DOI: http://doi.org/10.21698/simi.2017.0021 \\ NEW ECOLOGICAL SOLUTION TO IMPROVE THE LAKES CAPACITY BY COMBATING THE EXCESSIVELY DEVELOPED VEGETATION
}

\author{
Victorita Radulescu \\ University Politehnica of Bucharest, Faculty of Energy, 313 Splaiul Independentei, Sector 6, \\ Bucharest, Romania,vradul4@gmail.com
}

\begin{abstract}
The paper presents a solution designed and tested hydroelectric lakes, which have the useful volume reduced by $80 \%$ since the commissioning. The experimental prototype perfectly ecologic may be applied into hydropower lakes with complex utilization, including water supply for human necessities and cities. At the beginning are mentioned some responsible factors as the climate, hydrological, physical, and chemical for the lake's eutrophication. The vegetation developed so rapidly, diminishes quickly the water volume of the hydropower lakes, meaning less produced electric energy. Further, are presented the previous solutions tested, without any effect. This new solution, proposed as patent, is realized and tested in the Lake Pangarati. The main steps, challenges, and main solutions, during the utilization, are mentioned. Finally, in images are presented the obtained results, the real differences between shores with and without the barrier utilization. This new ecologically and friendly environment solution, to combat the excessive vegetation has a considerable efficiency and low costs. The main purpose is to rehabilitate the area and to reestablish the previous environmental conditions, taking into account that these two lakes Pangarati and Vaduri are RAMSAR sites since 2006. Finally, are mentioned some conclusions, acknowledgments, and references.
\end{abstract}

Keywords: biodegradation, environmental engineering, environmental monitoring, maintenance management, water conservation

\section{Introduction}

In the last decades, the national hydropower system confronts a new problem, excessive vegetation growth of in hydropower lakes. It seriously affects the ecological balance in the area (most affected are the fish) by the drop of the useful volume, water volume capacity decrease with economic effects (Nistreanu 1999).

The excessive hydropower resources use in the last 20-30 years due to the low cost of produced MW, led to a chain of negative effects (Seteanu 1998, 2004). Many SMEs have been developed in the recent years around lakes, using, and then spilling the water, leading to increased nitrites and nitrates concentrations. This explains why currently more than 20 lakes have a useful capacity reduced by over $80 \%$ (Bockman 2008, Turbatu 2004). In this category the rivers Bistrita and Jiu are included.

In this study three lakes on Bistrita, respective Pangarati, Vaduri, and Reconstructia are analyzed. As a first objective in order to solve this problem, was analyzing the environmental parameters from the critical areas, which led in time to excess vegetation grown. Analyses of sediments, chemical structure, biological conditions, temperatures, water flowrate, type of vegetation were carried out, as to estimate the real situation. 
During the past years different methods for combating the vegetation growth were experimented, but all of them failed. The adopted solution must be realized while taking into account the importance of continuous useful flow assurance through the transport channel (Radulescu 2004), the energy needed to be produced, but, also the water alimentation for the local population and for the downstream consumers.

The solution is an economic, ecologic, and efficient solution, by placing of "screens" above the plant roots, as to suffocate the existing vegetation. Shortly the vegetation turns into sludge, without regenerating, even in the next year. This means that even the seeds, the cuttings and the roots have been destroyed.

At each 3-4 weeks, the barrier is moved to a new location, adjacent to the old one. After one year, comparisons were made and the solution efficiency was evaluated by comparing the two shores (the one with the "screens" and the natural one).

\section{Materials and Methods}

Based on the tests realized during the last decade, it was observed that the excess vegetation development is due primarily to the existent sediments, as consequence of the repeated, registered floods between 2005-2012 (Rodhe 1969). Another cause is represented by the new appeared SMEs on the lake's shores. They use the water from the lake and render it, partially decontaminated. A particular problem occurs in the case of the companies that process the wood. The water which is returned to the lake contains a significant amount of nutrients, clearly advantageous for aquatic vegetation development (Smith, 1999; Horrigan, 2002).

Some remarks:

- The dissolved substances in water are the main arguments of aquatic vegetation development,

- The Carbon, after the Hydrogen and the Oxygen, represents the main component,

- The presence of the Phosphor assures a supplementary nutrient, larger than the presence of the Nitrogen compounds, due to the repeated floods,

- If large amounts of Phosphor are discharged into the hydrographical structure the phenomena induce a decrease of the Nitrogen compounds concentrations and consequently, Ciano-bacteria explodes in number (Bartram 1999),

- The Oxygen assures the reaction between the water and sediments; the cycle becomes repetitive and the excess bacteria appear. Moreover, there is only one-step to an excess vegetation growth.

In Table 1 some characteristics of the analyzed sediments are mentioned, as well as some average values obtained during the measuring campaigns. In Table 2 the available/necessary substances in the lake water for vegetation development are presented.

In these lakes the nutrients intake is too high, assuring the development of algae at this level, mainly due to the sediment transported from the upstream.

Many algae represent a first favorable aspect, the first step into developing of the aquatic vegetation. In short time, some species become dominant, with a major influence on the local ecosystems. The local flora becomes restricted, and some species of fish decrease dramatically in number.

In time, in the mentioned lakes different methods to combat the vegetation have been tested. 
Table 1. The average measured values

\begin{tabular}{c|ccc}
\hline Parameter & Lake I & Lake II & Lake III \\
\hline Humidity $\left(105^{0} \mathrm{C}\right) \%$ & 55.46 & 53.38 & 55.66 \\
$\mathrm{pH}($ up H) & 6.80 & 6.65 & 7.04 \\
Organic Substances $(\%)$ & 6.95 & 5,93 & 8,36 \\
Mineral substances & 93.05 & 94.07 & 91.64 \\
$\mathrm{NH}^{+}{ }_{4} \mathrm{mg} / 100 \mathrm{~g}$ & 5.85 & 7.27 & 8.01 \\
$\mathrm{NH}^{+}{ }_{4} \mathrm{mg} / \mathrm{L}$ & 105.48 & 136.19 & 143.91 \\
$\mathrm{NO}_{3}^{-} \mathrm{mg} / 100 \mathrm{~g}$ & 0.33 & 0.41 & 0.19 \\
$\mathrm{NO}_{3}^{-} \mathrm{mg} / \mathrm{L}$ & 5.95 & 7.68 & 3.41 \\
$\mathrm{PO}^{3-}{ }_{4} \mathrm{mg} / 100 \mathrm{~g}$ & 0.068 & 0.072 & 0.086 \\
$\mathrm{PO}^{3-}{ }_{4} \mathrm{mg} / \mathrm{L}$ & 1.22 & 1.34 & 1.54 \\
$\mathrm{~N}-\mathrm{NH}_{4}^{+}+\mathrm{N}_{-}-\mathrm{NO}{ }_{3} \mathrm{mg} / 100 \mathrm{~g}$ & 4.61 & 5.74 & 6.27 \\
$\mathrm{P}^{-\mathrm{PO}^{3-}}{ }_{4}(\mathrm{mg} / 100 \mathrm{~g})$ & 0.022 & 0.023 & 0.028 \\
$\mathrm{~N}_{\text {dissolved }} / \mathrm{P}_{\text {dissolved }}$ & 209.54 & 249.56 & 223.93 \\
\hline \multicolumn{3}{|c}{}
\end{tabular}

Table 2. The available/necessary values of chemical components

\begin{tabular}{c|cccc}
\hline Element & Symbol & $\begin{array}{c}\text { Consume } \\
\text { (vegetal) } \\
\text { \% }\end{array}$ & $\begin{array}{c}\text { Water offer } \\
\text { \% }\end{array}$ & $\begin{array}{c}\text { Consume/offer } \\
\text { (approx.) }\end{array}$ \\
\hline Oxygen & $\mathrm{O}$ & 80.5 & 89 & 1 \\
Hydrogen & $\mathrm{H}$ & 9.7 & 11 & 1 \\
Carbon & $\mathrm{C}$ & 6.5 & 0.0012 & 5.000 \\
Silica & $\mathrm{Si}$ & 1.3 & 0.00065 & 2.000 \\
Azoth & $\mathrm{N}$ & 0.7 & 0.000023 & 30.000 \\
Calcium & $\mathrm{Ca}$ & 0.4 & 0.0015 & $<1.000$ \\
Potassium & $\mathrm{K}$ & 0.3 & 0.00023 & 1.300 \\
Phosphor & $\mathrm{P}$ & 0.08 & 0.000001 & 80.000 \\
Magnesium & $\mathrm{Mg}$ & 0.07 & 0.0004 & $<1.000$ \\
Sulpha & $\mathrm{S}$ & 0.06 & 0.0004 & $<1.000$ \\
Chlorine & $\mathrm{Cl}$ & 0.06 & 0.0008 & $<1.000$ \\
Sodium & $\mathrm{Na}$ & 0.04 & 0.0006 & $<1.000$ \\
Iron & $\mathrm{Fe}$ & 0.02 & 0.00007 & $<1.000$ \\
Boron & $\mathrm{B}$ & 0.001 & 0.00001 & $<1.000$ \\
MangaN & $\mathrm{Mn}$ & 0.0007 & 0.0000015 & $<1.000$ \\
Zinc & $\mathrm{Zn}$ & 0.0003 & 0.000001 & $<1.000$ \\
Cuprous & $\mathrm{Cu}$ & 0.0001 & 0.000001 & $<1.000$ \\
Molybdenum & $\mathrm{Mo}$ & 0.00005 & 0.0000003 & $<1.000$ \\
Cobalt & $\mathrm{Co}$ & 0.000002 & 0.000000005 & $<1.000$ \\
\hline
\end{tabular}

\section{Chemical products}

1. Algaecides. Recommended to be used as the effective derivative of copper products on the surfaces covered by algae for their fast reaction. A mixture is uniformly sprayed over the infested water surface, preferably on a calm sunny day. The heavy infestations were treated, but only for small surfaces, in different stages, at intervals of 5-7 days, with rest between treatments as to avoid the oxygen depletion. The retreatment during the growing season is required, and it is most efficient if it is used when a new growth cycle begins. In the hydropower lakes, this solution could not be applied, due to the water use, as supply for the population.

2. Herbicides - Represent an effective systemic solution for the control of the aquatic vascular plants. This solution is effective when the water flow and discharge are 
minimal. The application is easy, by discharging into the water body at several locations. During the application plants should be actively growing, with the water temperatures above $15^{\circ} \mathrm{C}$. Moreover, the solution does not destroy algae and some other species. In many countries, this solution is completely forbidden. In the hydropower lakes, this solution could not be applied, due to the water use, as supply for the population .

\section{Biological additives}

Generally, the use of bio-augmentation inhibits algae growth, reduces odors, and reduces the sludge deposits while improving the water quality. These highly concentrated cultures of naturally occurring microbes destroy the algae. This solution, as the previous ones, could not be applied, due to the water use, as supply for the population. The solution was tested ten years ago in the lake but the Commissions of the Environmental Protection and of The Commission of Public Health have rejected it immediately.

\section{Mechanical control}

There are two different solutions:

1. Harvesters - remove the plants from the water and restore the water quality problems associated with a partial decay of the cut plants. These machines, after cutting, may remove the vegetation from the water with a conveyor system, and dispose of the collected plants onshore. They operate in depths of about $1 \mathrm{~m}$. Some of them are large enough to haul up to 13 tons of vegetation. Densely packed, the aquatic vegetation can weigh up to 200 tones for a lake with a surface of $100 \mathrm{~m}^{2}$. Sometimes, it is necessary to separate the shuttle barges from the harvester with an additional boat for the matter transport to the shore, while the harvester continues to work. Unfortunately, the machine also kills the fish, amphibians, reptiles, birds, and other wildlife by including them in the harvested material.

In the lakes Pangarati and Vaduri, considered for application, this solution cannot be applied; the lakes are Legal protected by the Decision 1266/2000. They were declared RAMSAR sites in 2006, included in Nature 2000 based on the EU Birds Directive, having the RoSPA0048 code.

2. Rotovator - uses the rototiller with blades to collect at $0.5-0.8 \mathrm{~m}$ of the bottom water, by extracting most of the plants. They are primarily used for plants that have buoyant roots, crowns. The loose floating plants and with roots are then collected and removed by an attachment to the machine, by the harvester, or by hand. Rotovators can clean large surfaces per day. Most often they should be used in winter or during spring when the plants have died. The control generally lasts two of the growing seasons. Rotovation is expensive and has large dimensions. The machines are difficult to be handled, consequently the bottom obstacles are problematic (as the rocks or in the areas where the bottom of the lake is variable). The rotovation severely disrupts the sediments, and can produce negative environmental impacts such as increased water turbidity, the release of nutrients from the sediments, the release of the toxic residues bound in the sediments, and disruption of the bottom dwelling of the aquatic animals, for fish, the spawning, and the migration. There are many countries where rotovators are not used. In the mentioned lakes, this solution cannot be applied; the lakes are Legal protected by Decision 1266/2000. The mechanical solutions are 
expensive and not efficient. Shortly, the floating vegetation develops new roots and starts a new cycle, being stronger than before and in a larger number (as grass cut in one-year next year is getting stronger, denser). Generally, the natural species are developing in natural rhythm; the invasive species grow faster.

\section{The Carp of grass}

The solution was tested by importing some carp species from China. The control and the use of such biological solution it is not well tested worldwide. In Romania, the solution was not efficient. Populating lakes with such fish was tried twice in Romania. They need an almost constant temperature to survive, of around $18-24^{\circ} \mathrm{C}$. In the mentioned lakes, for more than 7 months/year the temperature is around $10^{\circ} \mathrm{C}$ and generally, the surface freezes in winter; in these conditions, the fish died.

It was, therefore, necessary to find another solution, accepted by all users and without disturbing the environment.

\section{Results and Discussion}

The proposed solution is ecological and efficient, consisting is bottom barriers. Each panel is formed from three subsidiary ones, covering a surface of $72 \mathrm{~m}^{2}$. There are three years since the solution is tested with favorable results, for the water depth of 2 $4 \mathrm{~m}$, the main area where the vegetation grows. Such barrier or benthic barrier covers the sediments and the vegetation roots as a blanket, compressing the aquatic plants, and blocking light almost totally. The material that was used is Texel, a special material, a heavy plastic, used especially in highways; nowadays it has a new destination. In Fig. 1 one barrier is presented during transport, at the testing area the Lake Pangarati. The solution is compact and easy to be transported, manipulated, being modulated.
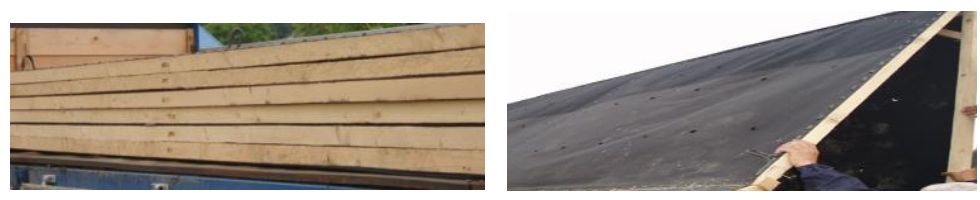

Figure 1. The bottom barrier

When the barrier is placed over vegetation must be checked that the natural water current or different animals do not move the panels. It must be anchored at corners, and at least in six other places. In order to decrease the final costs local stones are used as anchors, by being placed in special realized bags, from the same material (Texel). In order for the solution to be efficient, the material has to be black or dark material as to assure the impossibility of light penetration. The Texel is black. The time period for each lake bottom segment was selected at the beginning, of three weeks. The first barrier was made of compact material. In short time, due to the vegetation, which is "suffocated," large gas bubbles appeared, which couldn't be evacuated. On a routine inspection, the damages were observed. Initially, it was thought that some water animals destroyed the barriers. Only later, in an area where the released gases were still accumulated during the routine inspection and the barrier was entire, the cause of the damage was determined. In a second phase, the barrier was realized with many holes, as in Fig. 1-b. Time proved that the adopted solution is 
correct. The orifices must be small enough, to not let the light enter and to allow it to grow through the orifices (otherwise in time it will destroy the barrier) but large enough to let the gases to be evacuated at the lake surface.

This method may be used even from the beginning of the vegetation, early in March (Figure 2) especially for Elodeea Canadensis (the mainly developed aquatic plant) until the end of the November.
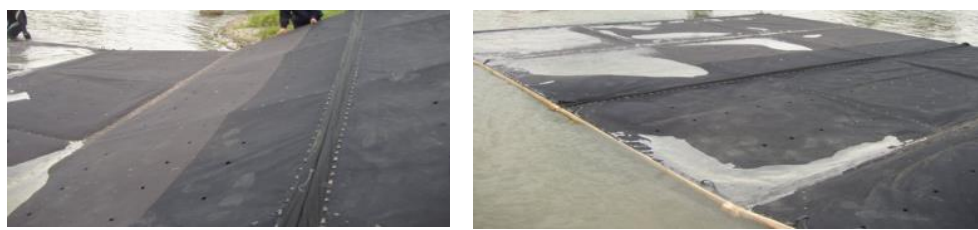

Figure 2. Image from the first site

In hydropower systems the massive vegetation appears at shallow waters, from the shores until 3-4 m. A boat and two divers carried out the barriers transportation. The first barrier was placed at the beginning of May 2014 and was left in the same position for a month. During the time it resulted that for May-June the barriers should be maintained in the same position for 3 weeks; during July-October the necessary timeframe is of one month (the vegetation already have grown and longer time is necessary for it to be destroyed). In this time, even the Elodea is destroyed. An area with a large amount of vegetation was selected. After a week, the first photos were made. Moreover, where the barrier was fixed, the vegetation changed its color. It does not grow, and it is not developing like into the rest of the lake. In June, the barrier was transported to another location. Once the anchors removed, the barrier floats at the surface. It is important to know the area of the barrier's influence. Through the barrier's holes partially destroyed vegetation appears. In Fig. 3-b, c the former vegetation, collected from the vicinity of the barrier is presented. The vegetation lacks roots and the color has already changed, the vegetation has another aspect, it is not fully green as a month before, and it became brown in many places, destroyed.

Due to the holes, the emanated gases during the decomposition process were evacuated, and the barrier looks well (Figure 3-a). After three weeks all types of plants have been suffocated and transformed in mud, due to darkness and the high temperature developed under the plastic material of the barrier (Figure 4-a). Even for a few meters around the barrier the vegetation is partially destroyed. The places where the barrier was installed are marked, in order to observe if next year the vegetation reappears. In places without the barrier, the vegetation grows normally. A massive amount may be observed, increased up to $20-30 \mathrm{~cm}$ of the surface. Basically, the divers fail to lift the arms with the vegetation that they can gather, in one motion (Figure 4-b).
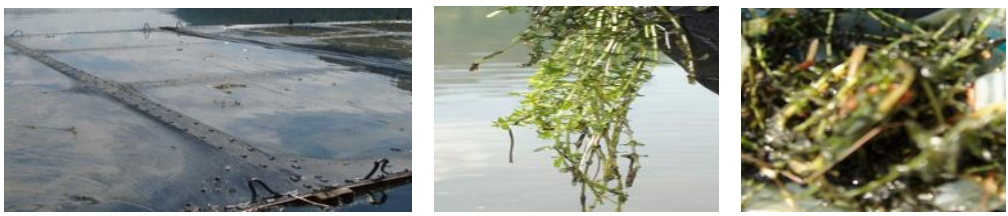

Section Pollution Assessment \& Management Systems 171 
Figure 3. Vegetation partially destroyed after one week

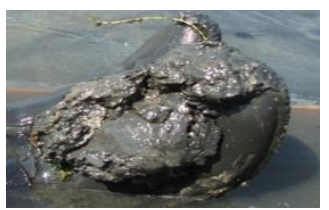

Figure 4. Images with and without barrier
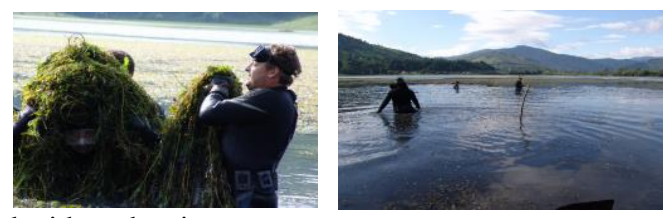

In Figure 4-c, an image taken two months after the replacement of the barrier from the initial place is presented. During this time, the vegetation didn't develop, remaining destroyed. In the area where the barrier was placed, a small amount of water free of vegetation can be observed (Figure 4-c).

\section{Conclusions}

The solution was developed and implemented in silted lakes at a rate of more than $80 \%$, in order to restore the ecological balance, without disturbing the environment. The solution is environmentally friendly meaning it does not affect the water quality. Under these circumstances, it can be used in the hydroelectric lakes where are catchments for water supply for cities and villages.

For the mentioned areas there are no other known classical solutions that could be used to control vegetation growth. In the areas where the bottom barriers were placed, in the following two years the vegetation didn't reappear, so basically a lake with clean water remains. This means that even the seeds have been destroyed. In a period of three - four weeks an area of about $100 \mathrm{~m}^{2}$ has cleaned, which remains clean at least for two years. There appeared no new development of aquatic vegetation. Using this solution boosted the fish regeneration, consequently of the animals that inhabited near water. No other solution with the same efficiency and with so low costs is known to date for this cases.

\section{Acknowledgements}

I would like to thank my colleagues from the SC Hidroelectrica SA, who presented me the problems appeared into these hydropower lakes, and supported me in the physic realization of the experimental solution and allow me to test it in Lake Pangarati for more than three years.

\section{References}

Bartram, J, Wayne, W, Carmichael, I \& Chorus, G 1999, Chapter 1. Introduction, In: Toxic Cyanobacteria in Water: A guide to their public health consequences, monitoring, and management, World Health Organization.

Nistreanu, V \& Nistreanu, V 1999, 'Amenajarea resurselor de apa si impactul asupra mediului', Editura Bren, Bucharest.

Radulescu, V \& Nistreanu, V 2004, 'Sisteme hidraulice de aductiune', Bren Publisher, Bucharest, ISBN 973-31-1412-X.

Rodhe, W 1969, 'Crystallization of eutrophication concepts in North Europe: Eutrophication, Causes, Consequences, Correctives', National Academy of Sciences, Washington D.C., Standard Book Number 309-01700-9, pp. 50-64. 
Seteanu, I \& Radulescu, V 2004, 'Numerical models in hydraulics and power engineering', Bren Publisher, Bucharest, ISBN 973-99604-4-8.

Seteanu, I, Radulescu V et al. 1998, 'Sisteme hidraulice, Fundamente si aplicatii', Editura Tehnica, Bucuresti, ISBN 973-31-1412-X.

Bockman, T \& Tom, H 2008, 'Investment timing and optimal capacity choice for small hydropower projects', Energy, Elsevier.

Horrigan, L., Lawrence RS \& Walker, P 2002, 'How sustainable agriculture can address the environmental and human health harms of industrial agriculture", Environmental health perspectives, pp. 445-456, doi:10.1289/ehp.02110445.

Radulescu V, Seteanu I 1999, 'Optimal policy of Exploiting of Irrigation-Drainage Systems of Wells', Comp. Heat and Mass Transfer, G. Magusa, Eastern Mediterranean University, ISBN 9758401009, 9789758401000.

Radulescu, V \& Zetenyi, Z et al. 2009, 'Utilization of renewable resources in rehabilitation of existent micro-hydro power plants', Conference Hydro, pp.156-163, Lyon, France.

Smith, VH, Tilman, GD \& Nekola, JC 1999, "Eutrophication impacts of excess nutrient inputs on freshwater, marine, and terrestrial ecosystems", Environmental Pollution, pp. 179-196, doi:10.1016/S0269-7491(99)00091-3, PMID 15093117.

Turbatu, A, Radulescu, V \& Abrudan, T 2004, 'Eficientizarea conducerii operative a centralelor hidroelectrice prin urmarirea on-line a parametrilor de functionare. Aplicatie la SH-Curtea de Arges', Revista Energetica, An.49, nr.89, pp. 432-436, ISSN 1220-5133. 